\title{
THE TREATMENT OF GENERAL PARALYSIS BY MALARIA
}

\section{Discussion}

Dr. NABARRo said that in this class of case it was of great importance that treatment should be started as soon as possible, and certainly before considerable and irreparable damage had been done to the brain and nerve tissues. It was therefore highly important that the cerebrospinal fluid should be examined in every case of syphilis, not only at the commencement of treatment but also at the end and before the patient could be discharged as being probably cured. In this way cases of neurosyphilis would be diagnosed and the appropriate treatment instituted. He did not consider it was safe to leave a child with a positive Wassermann Reaction in its cerebrospinal fluid, even after a long course of N.A.B. injections and mercury or bismuth, lest the patient should subsequently develop tabes or G.P.I. The condition of G.P.I. was difficult to diagnose in children because they rarely, if ever, showed the symptoms of exaltation and the tremors which occurred in adults, but usually there was a history of fits and of either mental backwardness or gradual deterioration. In making the pathological diagnosis one relied upon slight or moderate increases in the cells and protein content of the fluid, a positive Wassermann Reaction, and especially upon the paretic type of colloidal gold curve.

Fourteen children in all had been treated with malaria, but only four of these were probably cases of G.P.I. Seven of the fourteen were infected by mosquitoes and seven by injections of malarial blood. The incubation period seemed to vary according to the method employed. In four of the seven cases infected by mosquitoes the incubation period was fifteen days, and in the three other cases it was thirteen, fourteen and sixteen days respectively. In four of the cases in which blood was used to infect the incubation period was only ten days, in one it 


\section{TREATMENT OF PARALYSIS BY MALARIA}

was seven days and in another sixteen days. One case failed to take the infection after the first attempt with mosquitoes, but on the second attempt malaria developed in the ordinary way. In children the temperature usually shot up at once, and did not show the gradual rises which Dr. Nicol found in adults, and rigors did not, as a rule, occur in the earlier attacks of fever. The speaker had not seen a relapse among those children, which was a contrast to the 60 per cent. relapses Dr. Nicol mentioned. To stop the fever in children 2 grs. euquinine were given three times a day for five days, and after two days no parasites were found in the blood. He was not pleased with the effects of the treatment in children; he had treated four cases of G.P.I., but three of them had so far not shown any material benefit, and the Wassermann Reaction was still positive in the spinal fluid. Two years ago he recorded the case of a child, aged six, who developed G.P.I. rather acutely. One course of salvarsanised serum injections gave but little improvement. She was then given malaria, but it seemed to make her worse. Then he gave another course of intracisternal injections of salvarsanised serum, after which there was rapid improvement. Now, after an interval of eighteen months, the spinal fluid had become normal, but the blood Wassermann showed a slight relapse.

Four years ago he treated an adult with G.P.I. who was rather worse than the child just referred to. Two consultants considered the patient's condition was beyond treatment. He asked Sir James Purves Stewart to undertake the cisternal part of the treatment, and six injections of salvarsanised serum were given, with the result that both blood and spinal fluid became Wassermann-negative. The man had since been de-certified, was now apparently quite healthy physically, and normal mentally. Since his cure he had been to New Zealand twice by himself, and was now about to go for the third time. Possibly it may be found in the future that a combination of the two treatments was likely to give better results than malaria alone. He agreed with Sir James Purves Stewart that the object should be to render the cerebrospinal fluid negative.

With regard to T.A.B. vaccine treatment in children, this had been adopted in certain cases at Great Ormond Street to produce protein shock, but not in cases of con- 


\section{BRITISH JOURNAL OF VENEREAL DISEASES}

genital neuro-syphilis. It took considerably longer than did the malaria treatment.

He concluded by expressing the thanks of the Society to the two gentlemen who opened the debate.

Dr. S. C. Woodhouse thanked the speakers for their interesting papers, and paid a tribute to Dr. Nicol for his interest in the patients whom he had inoculated in the St. Thomas's Hospital Clinic. He would like to ask if any conclusions had been gathered regarding the decisive factor responsible for the beneficial results, which, by general consent, did occur in many general paralytics so inoculated. Dr. Woodhouse felt that favourable results were occasionally obtained with chemical pyrotherapeutic agents, such as sulfosin, in specific conditions other than G.P.I., which had not previously reacted to the usual methods of treatment. These agents were obviously safer to use and more readily controlled, but would they prove as efficacious as malarial therapy?

Mr. Dennis VinRace had hitherto regarded the subject of G.P.I. as incurable and a useless burden on the community, but the instructive papers read gave an inspiration of hope of material improvement, and culminating in at least one instance in fitness for married life. He gathered that N.A.B. had been administered in brain affections far more freely and with less anxiety than formerly and that good results were claimed.

Mr. WANSEY BAYLY said that the risk of malarial treatment should not, in his opinion, be considered in cases of general paralysis, with definite clinical symptoms, even in advanced cases where the general health had become markedly involved, as in such cases, even if the treatment showed a high death rate, the patient should not be denied the chance of long remission, perhaps even clinical cure, which was obtained in some cases. Desperate conditions justified desperate remedies.

What he would like to ask Dr. Nicol was, whether the percentage risk was markedly less in very early cases where the clinical symptoms were absent or very slight, or where the only evidence of central nervous involvement was a positive Wassermann and cell count of the C.S.F.?

Would Dr. Nicol consider that the risk of death following malarial treatment in such cases was so small as to justify such treatment as a routine in all cases where 


\section{TREATMENT OF PARALYSIS BY MALARIA}

ordinary anti-syphilitic treatment failed to have any noticeable effect on the pathological condition of the C.S.F., although there was no clinical evidence of general paralysis?

From Dr. MacKenzie's paper it appeared clear that typhoid vaccines could not be hoped to produce anything like the same degree of remission of symptoms frequently following malarial treatment. It was, however, very interesting to hear that typhoid pyrotherapy sometimes supplemented and increased the value of ordinary antisyphilitic treatment so as to greatly augment its effect both as regards clinical and pathological symptoms.

Dr. HANSCHELl said he began the malaria treatment five or six years ago with a series of cases of disseminated sclerosis, and later with cases of G.P.I. Dr. Nicol had stated that in the first slight initial fever the parasites, as a rule, could not be found ; that was true in the speaker's experience when he looked for the parasites only by the thin-film technique. By the thick-film technique he had always found them on the first day of the initial fever ; and twice by this method parasites were found one and two days respectively before the initial rise of temperature. Such a high percentage of cases of G.P.I. improved after malaria treatment, that now all cases with positive C.S.F. Wassermann should be given the treatment, even though physical signs and symptoms of G.P.I. and tabes were absent, and notwithstanding the risk to life involved ; for no other treatment at present held out any hopes of success.

Dr. MacKenzie's series of cases treated with T.A.B. were very interesting. $\mathrm{He}$, the speaker, had used T.A.B. intravenous injections for disseminated sclerosis eight years ago with no real or lasting amelioration of the disease ; and during the last three years for "latent" tertiary cases of syphilis, in which much anti-syphilitic treatment had failed to procure a negative blood-Wassermann. T.A.B. intravenous injections plus arsenobenzol and bismuth injections had procured a negative bloodWassermann, which so far had remained negative; but the number of these cases so dealt with was still too small to warrant any certain claims for that line of treatment, which also was risky, for that type of syphilis case had usually arterial disease like the G.P.I. cases.

A Speaker asked whether Dr. Nicol would give some 


\section{BRITISH JOURNAL OF VENEREAL DISEASES}

idea of how he got the good effects obtained in a number of cases in which pyrexia was the chief factor. Was there a better definite factor than malaria injection? In some cases arsenobenzol had given good results, also a clinical preparation of salvarsanised oil. One or two cases of interstitial keratitis did well, though they had been stationary previously to this treatment.

Dr. Buckley Sharp said he thought it very difficult to be certain about relapses. Children, for instance, were very liable to chills, accidental temperatures, etc., and relapses might not be typical malaria attacks. He had been somewhat disappointed in the results from malaria alone, though some of the cases treated by Dr. Nabarro had not been real G.P.I., but had been cases in which there had been an attempt to restore the cerebrospinal fluid to normal, and he did not remember a case in which malaria alone had achieved this object. That led him to the question of the serological results, in the cerebrospinal fluid, of malaria treatment. It was very encouraging to hear from Dr. Nicol that one-third of the cases were restored to useful life, discharged from the institution, etc., but he said nothing about the Wassermann, the Zange curve, and so on. He, the speaker, had been somewhat disappointed in the thirty cases so far done by Dr. MacKenzie. While T.A.B. pyrotherapy appeared less risky to life than malaria treatment, that was of small importance, because Dr. MacKenzie's were not so restored to useful life that they could be discharged from a mental hospital; their lives had been merely prolonged-a questionable virtue. He considered G.P.I. as being curable in favourable cases, not only clinically, so that normal life could be resumed, but also serologically. Recently he had a case which well illustrated the importance of the early diagnosis of G.P.I. The man came to the speaker because he did not feel in his usual health and could not concentrate as usual. Examination of the nervous system revealed nothing abnormal, but the speech was jerky and hesitant, with tremor of the tongue and lips, and there was difficulty in finding the suitable word when talking. Venereal infection was denied, even though the Wassermann was positive. He was found to have very high protein, positive Wassermann, globulin and increased cells in the cerebrospinal fluid. With such an early diagnosis the prognosis was 


\section{TREATMENT OF PARALYSIS BY MALARIA}

better than if the condition had gone on for months undiagnosed.

Mr. Hamish Nicol said that he would like to know whether the treatment by pyrotherapy, as given for general paralysis of the insane, had been tried in the cases of tabes dorsalis, and if so as to what the result had been?

Dr. F. CARMinow Doble congratulated the readers on their splendid papers. He wondered why malaria was first thought of as a treatment for G.P.I. He had examined a very large number of syphilitic natives in Uganda without seeing a single case of neurosyphilis. Amongst about I00,000 cases examined by the Commission, of which he was a member, no definite case of tabes or G.P.I. was seen. Was it due to the malaria that the natives acquired? Personally, he thought it was due to the acute primary and secondary manifestations the patients showed, the disease starting amongst the Baganda only thirty or forty years ago on virgin soil. The amount of their cutaneous reaction saved their cerebrospinal system.

He thought that intravenous T.A.B. was a safer form of treatment than malaria in, say, potential G.P.I. In advanced cases it did not seem to matter what the risk of malarial treatment was as long as there was any chance of improving the patient.

Dr. W. D. Nicol, in replying to the discussion, said that in going through some 400 cases which had been done through the Ministry of Health, some had failed to develop malaria, but he did not think it fair to say that those patients were really immune to malaria; indeed, he and his colleague had reached the conclusion that no cases in this country were really immune to malaria, as one had not yet failed to infect them finally. With regard to relapses among children, he did not know how long Dr. Nabarro kept the children at hospital, but, in the speaker's experience, short relapses were uncommon. In mental hospitals, cases were not ready for discharge until after seven months from the primary attack. He felt that many cases treated in general hospitals were sent out long before a relapse was likely. It was not uncommon to hear of cases which had been out of a general hospital and then returned to the out-patient department six or seven months later with a malarial relapse. 


\section{BRITISH JOURNAL OF VENEREAL DISEASES}

In answer to Dr. Wansey Bailey, there was risk in treating some advanced cases, but, excluding advanced cases, he did not consider the percentage risk was markedly less in the very early cases, where the clinical symptoms were absent or very slight. Cases of general paralysis, when sufficiently fit to risk the malaria treatment, should, he thought, be given the advantage of that treatment. In regard to treating cerebrospinal-positive cases apparently in good health, but who failed to react to ordinary anti-syphilitic treatment, he asked whether they were potential G.P.I. cases, and whether one was justified in giving them a course of treatment.

He agreed with Dr. Hanschell as to the thin-film technique, but there had been a few cases with a prolonged initial phase in which parasites had not been found after three or four days, even after examining thick films.

He was not in a position to express an opinion as to how malaria worked, except to say that malaria-inoculated cases appeared to give better results than those treated with blood.

With regard to serological differences in the cerebrospinal fluid, about sixty cases were supplied last year to Colonel Harrison when he was doing comparative tests with the Kahn reaction; some of those cases had been treated three or four years ago, but no negatives had been found amongst them. He had seen patients with a strong positive Wassermann who seemed practically cured, whereas other patients with a less strong positive had shown no improvement after treatment.

Referring to treatment of tabes, he had been told by several observers that malaria treatment seemed to afford some measure of arrest of the disease. He could not say whether malaria had a good effect on other syphilitic lesions, but it was rare to find cutaneous lesions in cases of general paralysis. All cases of the latter showed, post mortem, a diseased aorta, though during life nothing clinically directed attention to aortitis.

Dr. J. M. MACKenZIE also replied. He said that, in regard to a failure to secure a fall of temperature when there were present gross syphilitic lesions, in such tissues as gummata the fever might produce some form of resolution of the gumma, and the patient might be absorbing proteins which had been modified in the patient's tissues, though in the first place derived from them. Even such 


\section{TREATMENT OF PARALYSIS BY MALARIA}

a mild kind of auto-inoculation as a black-eye could cause some fever when the effusion was being absorbed. Possibly the absorption of gummata might be the cause of the prolongation of fever after vaccine injection. When delay occurred in cases of septic infection of some part, and there was a delayed fall of temperature, he thought the latter was due to absorption of the material which had been evolved as a result of stimulation of the tissues by vaccines.

In the present state of knowledge on this subject he was all against discharging these cases from care unless home conditions were good. He had discharged two patients to working-class homes in Birmingham. One of the men took to drink and allowed himself to get constipated, and then recommenced seizures. Eventually he had to be recertified. A similar event took place in the other case. As to what constituted " recovery," even in such a condition as appendicitis it varied a good deal, depending on the conservatism or the liberalism of the observer's mind. He had not seen a case of general paralysis actually cured. Some might keep clear of acute symptoms and appear harmless; some showed a degree of initiative. All, however, showed some feeble-mindedness, and this precluded the consideration of discharge, certainly in the class dealt with in Birmingham.

He thanked those present for their kindly reception of his paper. 